\title{
Penyaluran Kredit dan Tingkat Likuiditas: Bukti Empiris pada Bank Umum di Indonesia
}

\author{
Arnoldus Hesron Bhoka ${ }^{1}$, Sari Yuniarti ${ }^{2 *}$, Mohammad Burhan ${ }^{2}$ \\ ${ }^{1}$ Program Magister Manajemen Pascasarjana Universitas Merdeka Malang, Malang, \\ Indonesia \\ ${ }^{2}$ Fakultas Ekonomi dan Bisnis Universitas Merdeka Malang, Malang, Indonesia \\ *sari.yuniarti@unmer.ac.id
}

\begin{abstract}
This paper examines the effect of bank lending on liquidity. We use the loan-todeposit ratio as a proxy for liquidity and total loan as a proxy for bank lending. We also consider the measurement of liquidity with non-performing loans (NPL) and return on assets (ROA) as control variables. The sample used is the banks listed on the Indonesia Stock Exchange as many as 42 banks with a total of 184 observations from unbalanced panel data. The analysis used is panel data regression (generalized least squares) with random effects as the best estimation model. We find bank lending to have a positive effect on liquidity, especially for banks that go public. We argue that banks avoid bankruptcy by increasing the proportion of reserves to absorb risk. The results support the "risk absorption" hypothesis (Berger \& Bouwman, 2009). We also find that return on assets (ROA) has a significant effect on liquidity, but non-performing loans (NPL) have no significant effect on liquidity, proving that banks has managed their reserves by absorbing risk properly.
\end{abstract}

Keywords: Bank Lending, Liquidity, Non-performing Loans, Return on Assets, Risk-absorption Hypothesis

\section{PENDAHULUAN}

Peran bank dalam menjaga tingkat likuiditas menjadi penting bagi stabilitas perekonomian di suatu negara. Hal ini berkaitan dengan bank sebagai lembaga intermediasi yang memiliki kewajiban untuk menjaga simpanan dana dari pihak surplus dan menempatkan dana tersebut pada pihak yang membutuhkan (defisit). Ancaman likuiditas bank semakin meningkat apabila terjadi krisis ekonomi. Krisis keuangan barubaru ini telah mengungkapkan fakta bahwa jika bank tidak berkinerja baik, perekonomian tidak akan berjalan baik. Beberapa penelitian menemukan bahwa kegagalan bank untuk memenuhi kewajibannya dapat menyebabkan bank runs, sehingga memberi dampak pada kerusakan ekonomi yang semakin parah (Chouchène et al., 2017; Acharya \& Naqvi, 2010; Brunnermeier, 2010; Nyborg \& Österberg, 2010).

Menurut Bank for International Settlement (2008) likuiditas didefinisikan sebagai kemampuan bank untuk mendanai peningkatan aset dan memenuhi kewajibannya tanpa menimbulkan kerugian yang besar. Sedangkan Drehman dan Nikolau (2013) menyatakan bahwa likuiditas merupakan kemampuan bank untuk menyelesaikan kewajibannya dengan segera, pada saat jatuh tempo. Untuk mentransfer dana, bank perlu memilikinya, dan untuk 
memperoleh dana tersebut, bank harus memberikan jaminan kepada deposan bahwa mereka akan mendapatkan uangnya kembali, sesuai kesepakatan. Proses pemindahan dana dari unit ekonomi surplus ke unit yang memiliki peluang investasi, yaitu proses konversi aset tidak likuid menjadi liabilitas likuid dikenal sebagai penciptaan likuiditas oleh bank. Proses ini sangat penting untuk kelancaran fungsi perekonomian. Menurut Berger dan Bouwman (2009), bank menciptakan \$ 1 likuiditas ketika mengubah \$ 1 aset tidak likuid menjadi \$ 1 kewajiban likuid. Demikian pula, bank menghancurkan $\$ 1$ likuiditas dengan mengubah $\$ 1$ dari aset likuid menjadi \$ 1 kewajiban tidak likuid. Bank tidak menciptakan atau menghancurkan likuiditas ketika ia mengubah \$ 1 dari aset likuid menjadi \$ 1 dari kewajiban likuid atau $\$ 1$ dari aset tidak likuid menjadi $\$ 1$ dari kewajiban atau ekuitas yang tidak likuid.

Banyak penelitian mengenai likuiditas bank yang memberikan bukti tentang faktor dominan dalam meningkatkan likuiditas bank karena pentingnya bank dan likuiditasnya. Likuiditas yang baik sangat penting agar sistem perbankan dapat berfungsi dengan baik dan menyalurkan kredit ke sektor riil. Namun, beberapa bank di seluruh dunia menghadapi guncangan besar dalam pasokan likuiditasnya karena berbagai faktor salah satunya adalah bank lending (Kim \& Sohn, 2017; Chen et al., 2015). Ketika dana yang tersalurkan kepada masyarakat dalam bentuk kredit semakin besar, maka sisi likuiditas mempunyai tekanan tersendiri yakni persiapan cadangan pemenuhan modal bank agar tidak terjadi risiko likuiditas. Risiko likuiditas dapat terjadi ketika bank tidak dapat memenuhi permintaan penarikan dana dan permintaan kredit oleh nasabah (Djebali \& Zaghdoudi, 2020; Smaoui et al., 2020; Soula, 2017). Adanya risiko terkait dengan likuiditas membuat bank wajib memenuhi berbagai kepentingan masyarakat baik penarikan dana maupun permintaan dana (kredit).

Kredit merupakan salah satu faktor yang memengaruhi tingkat likuiditas bank. Penyaluran kredit memberikan pendapatan dari selisih nilai bunga kredit yang ditentukan dan masyarakat akan mendapatkan pinjaman dana dari bank dengan masa pengembalian dalam jangka waktu tertentu sehingga antara masyarakat dan bank mendapatkan manfaat serta keuntungan tersendiri. Penyaluran kredit merupakan sumber utama pendapatan bank dari nilai bunga kredit. Besaran pendapatan bank ini diberikan oleh debitur pada saat jatuh tempo. Perbankan merupakan perusahaan yang paling berisiko sehingga nominal besarnya pendapatan sebagian disisihkan untuk cadangan kerugian bank (Haq et al., 2019).

Dalam kamus Bank Indonesia, cadangan kerugian bank ini disebut dengan cadangan antisipasi yakni cadangan yang dibuat oleh bank untuk mengantisipasi adanya kerugian pada kegiatan bank yang paling berisiko yakni kredit. Cadangan bank ini akan memperkuat tingkat likuiditas dan menghindari risiko likuiditas. Adanya cadangan dari penyaluran kredit ini, membuat bank dapat melayani setiap transaksi nasabah baik penarikan dana maupun permintaan dana yang merupakan tolak ukur tingkat likuditas. Sejalan dengan hasil penelitian di Indonesia yang dilakukan oleh Pratama (2018) bahwa terdapat pengaruh yang signifikan antara penyaluran kredit terhadap likuiditas yakni semakin tinggi penyaluran kredit maka likuiditas juga semakin tinggi. Ini dapat berarti penyaluran kredit yang besar dapat memperkuat tingkat likuiditas (Meriläinen \& Junttila, 2020; Smaoui et al., 2020). Hackethal et al. (2010) membuktikan bahwa bank dengan pinjaman dalam jumlah besar menciptakan lebih banyak likuiditas, demikian pula dalam analisisnya terhadap bank-bank komersial yang terdaftar di Eropa dan Amerika Serikat. Angora dan Roulet (2011) berpendapat bahwa penciptaan likuiditas akan lebih rendah jika pemberian pinjaman terkonsentrasi pada pinjaman likuid. Hal senada juga dinyatakan oleh Meriläinen dan Junttila (2020), Smaoui et al. (2020), Horváth et al. (2014), serta Lei dan Song (2012) yang menyatakan bahwa pengaruh risiko kredit terhadap liquidity creation adalah positif. Namun pendapat ini berbeda dengan riset yang menemukan bahwa 
ketika penyaluran kredit meningkat, maka kemampuan bank dalam penciptaan likuiditas menurun. Hal ini dikarenakan penyediaan dana menjadi kecil, karena bank telah mentransformasi modal dan simpanan nasabah dalam bentuk penyaluran kredit (Diamond \& Rajan, 2001; Gorton \& Winton, 2017, 2000)

Ada 2 (dua) teori yang mendasari penelitian tentang penciptaan likuiditas, yaitu pertama, teori the "financial fragilitycrowding out" hypothesis (Diamond \& Rajan 2000, 2001; Gorton \& Winton, 2000). Teori ini didasarkan pendapat yang menyatakan bahwa penyaluran kredit oleh bank berdampak pada penurunan ketersediaan dana untuk deposan, karena proporsi dana dialokasikan lebih besar pada penyaluran kredit. Hal ini berdampak pada penurunan kemampuan likuiditas bank. Ini menandakan, semakin besar rasio permodalan bank apabila diiringi dengan jumlah penyaluran kredit yang semakin besar maka semakin menurunkan rasio likuiditas bank. Dengan demikian pengaruh penyaluran kredit terhadap likuiditas bank adalah negatif. Teori "financial fragility" yang dikemukakan oleh Diamond dan Rajan (2001) mengasumsikan bank tidak menyimpan atau menahan dana dari masyarakat, melainkan mengembalikan dana tersebut dalam bentuk penyaluran kredit kepada masyarakat yang produktif. Jika penyaluran kredit dilakukan secara gencar maka kemampuan bank untuk penciptaan likuiditas akan menurun. Teori "crowdingout" yang dikemukakan oleh Gorton dan Winton (2017, 2000) menjelaskan peningkatan rasio modal bank yang bersumber dari dana pihak ketiga akan cenderung meningkatkan kredit dan menurunkan likuiditas bank.

Kedua, the "risk absorption" hypothesis yang dikemukakan Berger dan Bouwman (2009) melihat dari pandangan yang berbeda. Peningkatan rasio modal bank akan diiringi dengan peningkatan bank untuk menahan dana dalam rangka meningkatan cadangan-cadangan untuk menyerap risiko. Hal ini memungkinkan bank untuk membuat kemampuan likuiditas semakin besar. Bank memiliki ketersediaan dana yang cukup apabila sewaktu-waktu deposan menarik dananya. Teori risk absorption memberikan asumsi bahwa semakin besar rasio modal yang diiringi dengan penyaluran kredit maka dapat membentuk likuiditas yang besar, memiliki hubungan yang positif. Hal ini dikarenakan semakin besar penyaluran kredit, maka bank akan mempersiapkan diri dari sisi likuiditas dengan meningkatkan cadangan pemenuhan modal bank agar tidak terjadi risiko likuiditas.

Penelitian ini bertujuan untuk menguji pengaruh penyaluran kredit terhadap likuiditas bank serta membuktikan penciptaan likuiditas bank-bank di Indonesia didasarkan pada asumsi the "financial fragility-crowding out" hypothesis atau the "risk absorption" hypothesis. Fenomena penting dari penelitian ini adalah mengidentifikasi bank-bank dalam mengantisipasi risiko likuiditas dan menjaga stabilitas perbankan di Indonesia.

\section{METODE}

Populasi dalam penelitian ini adalah semua perusahaan perbankan yang terdaftar di Bursa Efek Indonesia sebanyak 42 bank. Penelitian ini menggunakan data panel dengan jumlah data pengamatan (n) sebanyak 184 data (unbalanced panel data) yang diambil dari dokumentasi laporan keuangan tahunan bank periode tahun 2015-2019. Jenis penelitian ini adalah penelitian asosiatif kausal yang menggali pengaruh sebab akibat antara jumlah kredit yang disalurkan dengan tingkat likuiditas bank-bank yang go public di Indonesia.

Variabel dependen dalam penelitian adalah likuiditas bank yang diproksikan dengan loan-to-deposit ratio (LDR). Likuiditas berarti kemampuan bank setiap waktu untuk membayar utang jangka pendeknya apabila sewaktu-waktu ditarik oleh nasabah atau pihak-pihak terkait. Besar kecilnya modal dan jumlah penyaluran kredit yang dilakukan bank akan memengaruhi besar kecilnya tingkat penciptaan likuiditas. Tingkat likuiditas dapat diukur menggunakan rasio loan-to-deposit ratio (LDR) dengan rumus sebagai berikut: 
Loan to Deposit Ratio $=\frac{\text { Total loans }}{\text { Total deposit }+ \text { equity }} \times 100 \%(1)$

Variabel independen dalam penelitian ini yaitu jumlah kredit yang disalurkan. Kredit merupakan salah satu kegiatan operasional bank yakni dengan cara menyalurkan dana kepada masyarakat yang membutuhkannya. Akhir dari kredit adalah kewajiban debitur untuk membayar dana yang telah dipinjam tepat waktu dengan besaran bunganya kepada bank. Kegiatan kredit ini merupakan pengembangan bank dalam menjalankan fungsinya yang mewajibkan bank dalam menyalurkan dana yang telah dihimpun. Penyaluran kredit dapat dirumuskan sebagai berikut:

Total loans $=$ Ln $($ Total loans $)(2)$

Variabel kontrol dalam penelitian ada 2 variabel yaitu rasio profitabilitas yang diproksikan dalam return on assets (ROA) dan rasio kredit macet yang diproksikan dalam Non-performing loans (NPL). Profitabilitas merupakan rasio yang digunakan untuk mengukur kemampuan bank dalam menghasilkan keuntungan secara relatif dibanding dengan total asetnya. Rasio kredit macet (NPL) merupakan cara untuk mengukur besar kecilnya persentase kredit bermasalah pada suatu bank yang akibat dari ketidak lancaran nasabah dalam melakukan pembayaran angsuran Semakin kecil rasio NPL, semakin bagus kualitas kredit yang diberikan dan semakin kecil risiko tidak tertagihnya jumlah pinjaman yang disalurkan. Adapun rumus untuk menghitung ROA dan NPL adalah sebagai berikut:

Return on Asset $(R O A)=\frac{\text { Net profit }}{\text { Total asset }} \times 100 \%$ (3)

Non Performing loans $(N P L)=\frac{\text { The amount of bad debt }}{\text { Total loans }} \times 100 \%$ (4)

Teknik analisis yang digunakan dalam penelitian ini adalah analisis regresi data panel dengan bantuan program E-views 10 . Pemilihan data panel dikarenakan di dalam penelitian ini menggunakan rentang waktu beberapa tahun dan juga banyak perusahaan.
Pertama penggunaan data time series yaitu dari tahun 2015-2019. Kemudian penggunaan cross section itu sendiri karena penelitian ini mengambil data dari banyak perusahaan (pooled) yang terdiri dari 42 bank umum yang go public. Persamaan struktural regresi data panel ditunjukkan dalam persamaan sebagai berikut:

$L D R_{i t}=\alpha+\beta_{1} C R_{i t}+\beta_{2} R O A_{i t}+\beta_{3} N P L_{i t}+e_{i t}(5)$

Dimana:

$L D R_{i t}=$ Likuiditas

$C R_{i t}=$ Total loans/penyaluran kredit

$R O A_{i t}=$ Return on assets

$N P L_{i t}=$ Non-performing loans

$\alpha \quad=$ Intersep/konstanta

$\beta_{1,2,3}=$ Koefisien regresi

$e_{i t}=$ Error

\section{HASIL DAN PEMBAHASAN \\ Hasil Deskriptif Statistik}

Analisis deskriptif digunakan untuk menggambarkan atau mendeskripsikan variabel-variabel dalam penelitian ini dilihat dari nilai rata-rata, standar deviasi, nilai maksimum dan nilai minimum. Variabel yang digunakan dalam penelitian ini adalah loanto-deposit ratio (LDR), total loan, nonperforming loans (NPL) dan return on assets (ROA). Hasil olahan statistik deskriptif disajikan pada Tabel 1.

Tabel 1. Statistik Deskriptif

\begin{tabular}{|c|c|c|c|c|c|c|}
\hline Variables & $\mathrm{N}$ & Maximum & Minimum & Mean & Median & $\begin{array}{l}\text { Std. } \\
\text { Dev }\end{array}$ \\
\hline $\begin{array}{l}\text { Loan-to- } \\
\text { deposit }\end{array}$ & & & & & & \\
\hline ratio & 184 & 4115,57 & 60,61 & 87,77 & 87,50 & 11,08 \\
\hline $\begin{array}{l}\text { Total loans } \\
\text { Non- } \\
\text { performing }\end{array}$ & 184 & $4 \quad 25,32$ & 1,71 & 16,06 & 15,80 & 2,13 \\
\hline $\begin{array}{l}\text { loans } \\
\text { Return on }\end{array}$ & 184 & 9,92 &, 01 & 2,07 & 1,76 & 1,57 \\
\hline assets & 184 & $4 \quad 23,80$ & $-2,72$ & 1,78 & 1,12 & 3,78 \\
\hline
\end{tabular}

Berdasarkan hasil olah deskripsi statistik (Tabel 1), rata-rata nilai loan-todeposit ratio bank-bank yang go public sebesar $87,77 \%$ adalah dalam kategori baik karena dalam batas ketentuan yang ditetapkan oleh Bank Indonesia (BI) yaitu antara 80$110 \%$. Sedangkan rata-rata nilai non- 
performing loans sebesar 2,07 dinilai sangat baik karena tidak melebihi ketentuan BI sebesar 5\%. Rata-rata nilai return on assets sebesar 1,78 dinilai baik karena di atas 1,45\%.

\section{Hasil Pengujian Estimasi Pemilihan Model Regresi Data Panel}

Dalam memilih estimasi data panel yang digunakan, diperlukan untuk melakukan Uji Chow untuk memilih antara Common Effect Model (CEM) atau Fixed Effect Model (FEM) dan Uji Hausman untuk memilih antara Fixed Effect Model (FEM) atau Random Effect Model (REM). Hasil Uji Chow menghasilkan nilai Probability $F$ sebesar 0,4987>0,05, sehingga model yang dipilih adalah Common Effect Model (CEM). Oleh karena itu uji berikutnya dilanjutkan dengan Uji Hausman. Berdasarkan Uji Hausman diperoleh bahwa nilai Probability $\mathrm{F}$ sebesar 0,1928>0,05, sehingga model yang dipilih adalah Random Effect Model (REM). Oleh karena itu berdasarkan Uji Chow dan Uji Hausman, disimpulkan dalam penelitian ini menggunakan Random Effect Model (REM).

\section{Uji Asumsi Klasik : Normalitas}

Uji normalitas dalam penelitian ini menggunakan program E-views 10. Normalitas sebuah data dapat diketahui dengan membandingkan nilai Jarque-Bera (JB) dan nilai Chi-Square. Berdasarkan olah data diperoleh nilai probability Jarque-Bera sebesar 2,942 dan nilai probability ChiSquare sebesar 0,2296, dimana 2,924> 0,2296 , yang berarti data berdistribusi secara normal.

\section{Uji Asumsi Klasik : Multikolinearitas}

Berdasarkan hasil pengujian multikolinearitas dapat diperoleh tiga nilai koefisien korelasi $\left(\mathrm{R}^{2}\right)$ untuk total loan, NPL, dan ROA dengan masing-masing yakni $0,142075,-0,100555$ dan $-0,365815$. Dari ketiga nilai koefisien korelasi $\left(\mathrm{R}^{2}\right)$ tersebut lebih kecil dari 0,80 dan dapat disimpulkan bahwa dalam model ini tidak terjadi multikolinearitas.

\section{Uji Asumsi Klasik: Heteroskedastisitas}

Berdasarkan pengujian heteroskedastisitas dapat diperoleh tiga nilai probability dari total loans, NPL, dan ROA masingmasing yakni $0,1231,0,5158$ dan 0,4845 . Ketiga nilai probability lebih besar dari 0,05 maka dapat disimpulkan bahwa tidak terjadi masalah heteroskedastisitas.

\section{Hasil Pengujian Regresi Data Panel Pendekatan Generalized Least Squares}

Hasil pengujian regresi data panel menggunakan 2 (dua) model pengujian yaitu uji $\mathrm{F}$ (simultan) dan Uji t (parsial). Uji F merupakan pengujian hubungan regresi secara simultan yang bertujuan untuk mengetahui apakah seluruh variabel independen bersama-sama mempunyai pengaruh yang signifikan terhadap variabel dependen. Uji t digunakan untuk menguji hipotesis secara parsial guna menunjukkan pengaruh setiap variabel independen secara individu terhadap variabel dependen. Tabel 2 menyajikan hasil uji regresi data panel.

Tabel 2. Hasil Analisis Regresi Data Panel Pendekatan Generalized Least Squares

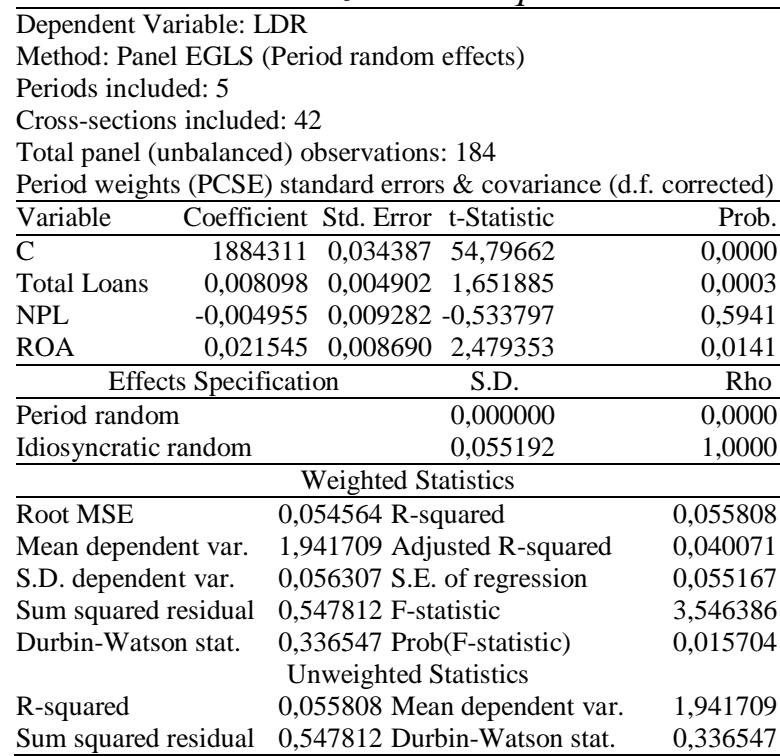

Berdasarkan Tabel 2, diperoleh nilai probability $\mathrm{F}$ statistic sebesar 0,015704. Terlihat bahwa nilai probability $\mathrm{F}$ statistic $0,015704<0,05$. Hal ini menunjukkan bahwa variabel total loan, NPL dan ROA secara simultan berpengaruh signifikan terhadap variabel LDR. 
Berdasarkan Tabel 2 diperoleh hasil pengaruh penyaluran kredit (total loan) terhadap LDR diperoleh nilai probability sebesar 0.0003 dimana nilai ini signifikan karena lebih kecil dari $\alpha=0,05$, yang bermakna bahwa penyaluran kredit berpengaruh signifikan terhadap LDR. Sedangkan pengaruh variabel kontrol nonperforming loans (NPL) diperoleh nilai probability sebesar 0,5941 dimana nilai ini tidak signifikan karena lebih besar dari $\alpha=$ 0,05 , yang berarti bahwa NPL tidak berpengaruh signifikan terhadap LDR. Hasil dari ROA diperoleh nilai probability sebesar 0,0141 dimana nilai ini signifikan karena lebih kecil dari $\alpha=0,05$, yang berarti bahwa ROA berpengaruh signifikan terhadap LDR. Berdasarkan hasil pengujian regresi data panel, maka terbentuk persamaan struktural regresi data panel dengan pendekatan Generalized Least Squares adalah:

$$
\begin{aligned}
L D R= & 1,884+0,0080 C R-0,0049 N P L \\
& +0,0215 R O A+e
\end{aligned}
$$

\section{Pembahasan}

Hasil penelitian menunjukkan bahwa penyaluran kredit berpengaruh terhadap likuiditas bank-bank umum yang go public di Indonesia. Hasil penelitian ini sejalan dengan penelitian yang dilakukan oleh Pratama (2018). Hasil penelitian ini juga mendukung Meriläinen dan Junttila (2020), Smaoui et al. (2020), serta Hackethal et al. (2010) yang mengatakan bahwa semakin besar penyaluran kredit maka tingkat likuiditas akan semakin baik. Penelitian juga mendukung teori risk absorption hypothesis (Berger \& Bouwman, 2009), penyaluran kredit berpengaruh positif terhadap likuiditas. Ketika rasio modal meningkat, maka sebagian akan dialokasikan dalam bentuk kredit. Penyaluran kredit akan memicu bank mencari sumber pendanaan untuk membentuk cadangan-cadangan yang digunakan untuk menyerap risiko, sehingga likuiditas bank meningkat. Di samping itu, dikarenakan kredit yang diberikan bank merupakan salah satu aktiva produktif yang dapat memberikan keuntungan bagi bank. Keuntungan tersebut dapat diambil dari persentase bunga yang sudah ditetapkan bank sesuai dengan standar dan kebijakan Bank Indonesia selaku otoritas tertinggi perbankan di Indonesia.

Penyaluran kredit menjadi kewajiban yang harus dilaksanakan oleh bank. Penyaluran kredit dilaksanakan atas dasar dana yang disimpan di bank yang merupakan hak masyarakat atau nasabah. Bank menyalurkan kredit karena bank mempunyai fungsi intermediasi yakni menyalurkan dana kepada masyarakat yang kekurangan dana, dari mayarakat yang kelebihan dana. Sehingga dana atau uang yang ada di bank tidak menganggur dan tidak digunakan. Dana tersebut disalurkan kepada masyarakat agar bank mendapatkan keuntungan atau laba sehingga dana tersebut dapat diputar terusmenerus baik sebagai kredit maupun sebagai penyediaan dana ketika nasabah melakukan penarikan. Kesanggupan bank dalam menyetujui penyaluran dana (kredit) dan penarikan dana merupakan tolok ukur tingkat likuiditas bank. Selain memberikan pinjaman dana untuk mendapatkan keuntungan, bank juga perlu waspada dengan menyediakan dana ketika nasabah melakukan penarikan dana baik dalam jumlah yang kecil maupun besar.

Kredit juga merupakan sumber utama pendapatan bank karena selain mengeluarkan dana untuk keperluan pinjaman nasabah, kredit juga dapat memberikan keuntungan. Keuntungan tersebut digunakan bank untuk disisihkan pada cadangan yang disebut oleh bank sebagai cadangan antisipasi. Setiap laba tahunan yang dihasilkan akan disimpan sebagian sebagai cadangan sebelum laba tersebut dibagikan kepada investor. Cadangan antisipasi ini dapat menggantikan dana yang dikeluarkan untuk menambah likuiditas bank.

Hasil penelitian ini juga menunjukkan bahwa NPL tidak berpengaruh terhadap likuiditas bank-bank umum yang go public di Indonesia. NPL merupakan rasio keuangan yang digunakan untuk mengukur tingkat kredit macet atau kredit bermasalah. NPL yang tinggi dapat menggambarkan bahwa bank kurang berhati-hati dalam menangani kredit bermasalah sehingga masuk dalam 
kategori kredit macet. Kredit macet atau kredit bermasalah merupakan indikator ketidakmampuan debitur atau nasabah untuk membayar utang tepat pada waktunya baik sebagian maupun semuanya. Besarnya NPL menunjukkan bahwa banyak piutang bank yang tidak tertagih sehingga bank mengalami kerugian dan mengganggu likuiditas bank.

Hasil penelitian ini tidak sejalan dengan Yurttadur et al. (2019), Yuniarti et al. (2018), dan Pop et al. (2018) yang menemukan bahwa semakin tinggi NPL akan semakin memperburuk likuiditas bank. Namun hasil penelitian ini sejalan dengan penelitian yang dilakukan oleh Fadillah et al. (2018), Kartini dan Nuranisa (2014), serta Santoso dan Sukihanjani (2013), yang menyatakan bahwa NPL tidak berpengaruh terhadap likuiditas. Hasil ini dapat disebabkan oleh NPL bagi bank merupakan risiko jangka pendek yang dapat diselesaikan dengan berbagai strategi bank diantaranya konsultasi dengan pihak debitur dan penjadwalan ulang waktu pembayaran. Risiko jangka pendek merupakan risiko yang dapat diatasi oleh bank dalam waktu singkat sehingga besaran NPL dapat diatasi dengan strategi bank tersebut dan bank tetap menjalankan penyaluran kredit serta melayani penarikan dana oleh nasabah. Strategi bank ini diharapkan dapat mengatasi tingginya NPL. Jika strategi tersebut tidak dapat mengatasi NPL, maka penyitaan dan pelelangan jaminan adalah penyelesaian terakhir untuk menutupi besaran kredit macet.

Strategi awal bank mengeluarkan peraturan bahwa nasabah yang melakukan usulan permintaan dana atau pinjaman harus disertai dengan jaminan atau agunan yang nilainya lebih besar dari nilai pinjaman (kredit). Sehingga ketika nasabah tidak dapat mengembalikan utang bank sepenuhnya atau sebagian, bank dapat menjual jaminan tersebut untuk menutupi kerugian yang dihasilkan. Kembalinya dana bank dari penjualan jaminan dari debitur dapat menyebabkan tidak signifikannya NPL karena kerugian bank telah ditutup dengan jaminan yang nilainya lebih besar dari kredit. Faktor lain yang juga menjadi penyebab tidak berpengaruhnya NPL terhadap likuiditas disebabkan oleh rata-rata tingkat NPL bank umum yang go public pada tahun 2015-2019 sebesar 2,08 dan masih berada di bawah 5\% sesuai dengan ketentuan yang berlaku untuk perbankan di Indonesia serta membuktikan bahwa bank mampu menekan dan mengelola kredit macet atau kredit bermasalah dengan baik. Sehingga peningkatan NPL pada kondisi ini tidak memberikan pengaruh yang signifikan terhadap likuiditas.

Berdasarkan hasil penelitian terbukti bahwa ROA berpengaruh positif dan signifikan terhadap likuiditas bank-bank umum yang go public di Indonesia. ROA merupakan ukuran tingkat keuntungan bank. Rasio ROA dapat menunjukkan bahwa bank mampu mengoptimalkan aktiva yang dimiliki untuk menghasilkan keuntungan. Dari hasil uji statistik dapat disimpulkan bahwa ROA berpengaruh positif dan signifikan terhadap likuiditas. Hasil Penelitian ini sejalan dengan penelitian yang dilakukan oleh Duan et al. (2021) juga Santoso dan Sukihanjani (2013) yang menyatakan bahwa jika ROA semakin besar maka semakin besar pula tingkat keuntungan yang diperoleh bank sehingga dapat menopang modal bank untuk dapat memperlancar kegiatan operasional bank khususnya dalam hal penjagaan tingkat likuiditas. Artinya semakin tinggi tingkat keuntungan (ROA) maka likuiditas juga semakin baik atau tinggi. Bank yang mempunyai tingkat laba yang tinggi menandakan bahwa dapat mengelolah seluruh aktiva dengan efektif dan efisien. Keuntungan bank didapatkan dari selisih bunga kredit, biaya administrasi, provisi dan komisi, penerbitan Letter of Credit $(L / C)$ dan lainlain. Keuntungan tersebut dapat digunakan sebagai penguat modal dan kelancaran kegiatan operasional bank yang didalamnya termasuk tingkat likuiditas, dimana bank mampu melayani ketika nasabah melakukan pinjaman dana maupun penarikan dana. Oleh karena itu dapat dikatakan bahwa semakin tinggi ROA maka tingkat likuiditas bank juga akan semakin tinggi dan terjaga. 


\section{Kesimpulan}

Penelitian ini bertujuan untuk menguji pengaruh penyaluran kredit terhadap likuiditas bank-bank umum yang go public di Indonesia. Hasil penelitian membuktikan bahwa penyaluran kredit berpengaruh positif terhadap likuiditas. Hasil penelitian ini mendukung teori risk absorption hypothesis dari Berger dan Bouwman (2009) yang mengemukakan bahwa semakin besar rasio modal yang diiringi dengan peningkatan penyaluran kredit dapat membentuk likuiditas yang besar. Hal ini dikarenakan semakin besar penyaluran kredit, maka bank akan mempersiapkan diri dari sisi likuiditas dengan meningkatkan cadangan pemenuhan modal bank agar tidak terjadi risiko likuiditas. Dari hasil penelitian ini terhadap variabel kontrol menemukan bahwa ROA berpengaruh positif terhadap likuiditas, namun NPL tidak berpengaruh terhadap likuiditas.

\section{DAFTAR PUSTAKA}

Acharya, V., \& Naqvi, H. (2010): The seeds of a crisis: A theory of bank liquidity and risk-taking over the business-cycle. Working Paper.

Angora, A., \& Roulet, C. (2011) Transformation risk and its determinants: A new approach based on the Basel III liquidity management framework. Working Paper. Université de Limoges.

Brunnermeier, M. (2010): Deciphering the liquidity and credit crunch 2007-2008. Working Paper.

Berger, A. N., \& Bouwman, C. H. S. (2009). Bank liquidity creation. Review of Financial Studies, 22(9), 3779-3837.

Chen, T. H., Chou, H. H., Chang, Y., \& Fang, H. (2015). The effect of excess lending on bank liquidity: Evidence from China. International Review of Economics and Finance, 36, 54-68.

Chouchène, M., Ftiti, Z., \& Khiari, W. (2017). Bank-to-bank lending channel and the transmission of bank liquidity shocks: Evidence from France. Research in International Business and Finance, 39,940-950.
Diamond, D. W., \& Rajan, R. G. (2001). Liquidity risk, liquidity creation, and financial fragility: A theory of banking. Journal of Political Economy, 109(2), 287-327.

Djebali, N., \& Zaghdoudi, K. (2020). Threshold effects of liquidity risk and credit risk on bank stability in the MENA region. Journal of Policy Modeling, 42(5), 1049-1063.

Drehman, M., \& Nikolau, K. (2013). Funding liquidity risk. Definition and management. ECB Working Paper Series, (December), 1-31.

Duan, Y., Fan, X., Li, X., Rong, Y., \& Shi, B. (2021). Do efficient banks create more liquidity: International evidence. Finance Research Letters. (In Press).

Fadillah, N., Aji, E. S., \& Tony. (2018). Pengaruh Faktor Internal Dan Inflasi Terhadap Likuiditas pada Bank Pembangunan Daerah di Indonesia. Jurnal Ilmu Manajemen (JIM), 6(3), 323-332.

Gorton, G., \& Winton, A. (2017). Liquidity provision and the social cost of bank capital. Journal of Money, Credit and Banking, 49(1), 5-37.

Gorton, G., \& Winton, A. (2000) Liquidity provision, bank capital and the macroeconomy. Working Paper. University of Minnesota.

Hackethal, A. Rauch, C. Steffen, S. \& Tyrell, M. (2010). Determinants of bank liquidity creation (October). SSRN Electronic Journal.

Haq, S. A., Tran, D. V., \& Kabir Hassan, M. (2019). Discretionary loan loss provision behaviour and banks' liquidity creation. Asian Academy of Management Journal of Accounting and Finance, 15(2), 119-154.

Horváth, R., Seidler, J., \& Weill, L. (2014). Bank capital and liquidity creation: Granger-Causality Evidence. Journal of Financial Services Research, 45(3), 341-361.

Kartini, \& Nuranisa, A. (2014). Pengaruh Capital Adequacy Ratio (CAR), NonPerforming Loans (NPL), Pertumbuhan 
Dana Pihak Ketiga (DPK), biaya operasional terhadap likuiditas yang diukur dengan loan to deposit ratio pada perusahan perbankan yang tercatat di Bursa Efek Indonesia. Unisia, 36(81), 142-156.

Kim, D., \& Sohn, W. (2017). The effect of bank capital on lending: Does liquidity matter? Journal of Banking and Finance, 77, 95-107.

Lei, A. C. H., \& Song, Z. (2012). Liquidity creation, bank capital structure and bank performance in China. SSRN Electronic Journal.

Meriläinen, J. M., \& Junttila, J. (2020). The relationship between credit ratings and asset liquidity: Evidence from Western European banks. Journal of International Money and Finance, 108, $1-21$.

Nyborg, K., \& Österberg, P. (2010): Money and liquidity in financial markets. Working Paper.

Pop, I. D., Cepoi, C. O., \& Anghel, D. G. (2018). Liquidity-threshold effect in non-performing loans. Finance Research Letters, 27, 124-128.

Pratama, A. A. P. (2018). Modal bank, tingkat likuiditas bank,dan pertumbuhan kredit (Bank capital, liquidity level, and lending growth). SSRN Electronic Journal.

Santoso, A. L., \& Sukihanjani, T. (2013). Analisis faktor-faktor yang mempengaruhi likuiditas perbankan di Indonesia. Prosiding $3^{\text {th }}$ Sustainable Competitive Advantage, 3(1).

Smaoui, H., Mimouni, K., Miniaoui, H., \& Temimi, A. (2020). Funding liquidity risk and banks' risk-taking: Evidence from Islamic and conventional banks. Pacific Basin Finance Journal, 64, 1-15

Soula, J. L. (2017). Measuring heterogeneity in bank liquidity risk: Who are the winners and losers? Quarterly Review of Economics and Finance, 66, 302313.

Yuniarti, S., Chandrarin, G., \& Subiyantoro, E. (2018). The direct and indirect impacts of good corporate governance on banking stability: An empirical study in Indonesia. International Journal of Business and Society, 19(S4), 517-534. Yurttadur, M., Celiktas, E., \& Celiktas, E. (2019). The place of non-performing loans in the Turkish Banking Sector. Procedia Computer Science, 158, 766771. 